\title{
Developing the model of normal operation of starter motor traction relays
}

\author{
Andrey Puzakov* \\ Orenburg State University, Pobedy avenue, 13, Orenburg, Russia
}

\begin{abstract}
Malfunction of motor starter traction relays cause the impossibility of the reliable start of internal combustion engines which, if the worst comes to the worst, can create the risk of traffic accident occurrence. Electric resistances of traction relay coils are structural and diagnostic parameters at the same time. Emergence and development of failures causes the change of magnetomotive force generated by the traction relay coils. Critical values of electric resistances correspond to failures of traction relay coils, i.e., inability to perform the built-in functions. The developed mathematical model of traction relay normal operation includes the amount of effort generated and voltage loss on contacts as controlled values for the drive mechanism and the starter electric motor, respectively. The results obtained contribute to the development of the method of motor-and-tractor starter diagnostics without removing it from the engine.
\end{abstract}

\section{Introduction}

A car, as a complex system of interacting elements, aggregates and mechanisms, provides its functioning due to the in-built reliability and overhaul ability, on the one hand, and improving the methods of technical impact on wheeled transport, on the other part.

Despite the high reliability, the technical condition of vehicle aggregates, systems, units, and parts changes in operation conditions, and failures occur from time to time.

The large share of electric equipment failures is explained by permanently enhancing nomenclature of products, the increase of their technical complexity, and is coordinated with the data of other researchers. From $25 \%$ to $34 \%$ of all failures account for the car electric equipment, and up to $30 \%$ time costs account for their elimination [1], [2], [3].

A motor starter, serving for communicating the initial rotation frequency to an internal combustion engine, is a rather reliable device with the service life comparable to that or a car. However, in the process of operation, malfunctions occur in starters sooner or later, causing their failure rather frequently. The motor starter failure automatically leads to the impossibility to pull away, which, if the worst comes to the worst (for example, at the car sudden stop on a busy intersection or a railway crossing), can create the risk of traffic accident occurrence. Consequently, a need for timely determination of the motor starter technical condition without removing it from the engine appears.

In the composition of motor-and-tractor starters, the following components are usually distinguished: an electric motor serving for communicating the driving torque to the internal combustion engine (ICE) flywheel; a drive mechanism bringing the gear in mesh with the flywheel, and a traction relay, first, transferring the fore to the starter drive mechanism, and second, connecting the electric motor to the battery pack.

The main motor-and-tractor starter malfunctions are: breakages and short circuits of electric motor coils (13\%), free-wheeling clutch slipping (10\%), starter drive mechanism gumming (12\%), wear of bushing and brush barrels $(21 \%)$, failure of the cushioning spring $(5 \%)$ and the in-built reducer $(9 \%)$, damage of the gear teeth $(7 \%)$, traction relay malfunction (18\%) and others [4], [5], [6], [7], [8], [9], [10], [11], [12], [13], [14], [15], [16], [17].

Thus, the traction relay efficiency directly impacts on the ICE startup possibility. The objective of this study is analyzing the block diagram of motor-and-tractor starter traction relays and developing the mathematical model of normal operation on its basis.

The structure of malfunctions of automobile starter traction relays is given in Figure 1 [18].

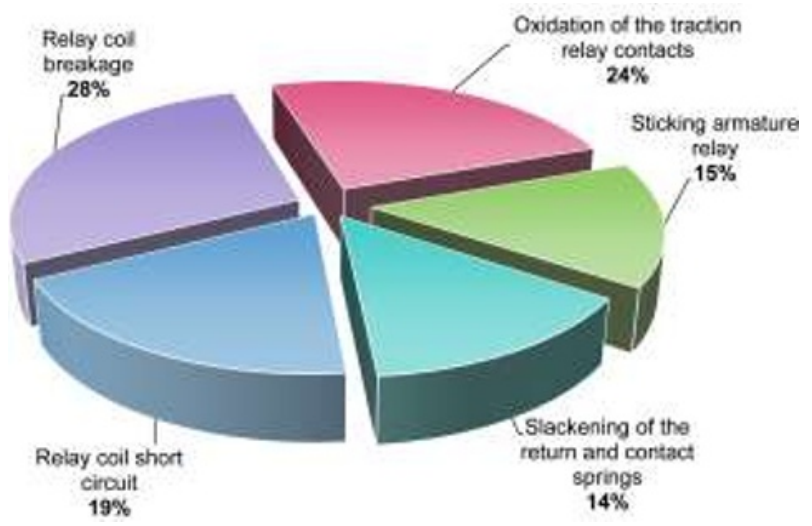

Fig. 1. Structure of malfunctions of motor-and-tractor starter traction relays.

\footnotetext{
* Corresponding author: And-rew78@yandex.ru
} 


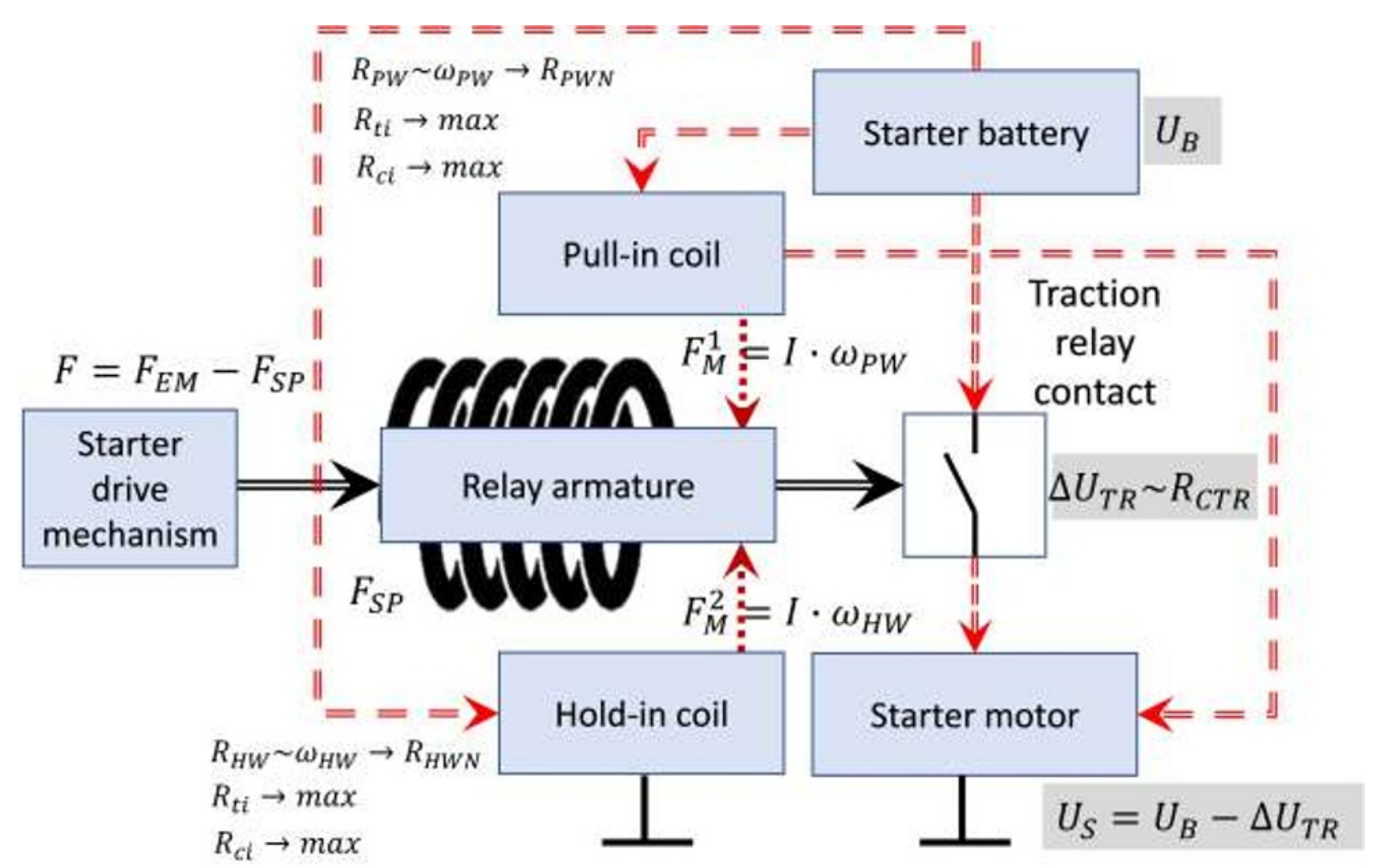

Fig. 2. Starter traction relay block diagram.

\section{Mathematical model development}

The Figure 2 shows the block diagram of motor-andtractor starter traction relays, judging from which, the traction relay elements connected with the electric (electromagnetic) energy current, form a closed circuit. Consequently, the deviation of operating parameters of any of these elements (the extreme case is failure) will cause the reduction of the probability of ICE reliable startup. It can be said that the traction relay has the series-shunt network of reliability [1].

Traction relay coil is characterized by structural and diagnostic parameters: weight, size, electric resistance, insulation resistance, coil temperature [18].

The traction relay pull-in coil is intended for generating magnetomotive force, consequently, the following transformations can be performed.

$$
\left\{\begin{array}{c}
F_{E M} \equiv F_{M}^{2} \\
F_{M}=I \cdot w_{P W} \\
I=\frac{U_{B}}{R_{P N}} \\
F_{M}=\frac{U_{D} \cdot w_{P W}}{u_{P W}}
\end{array},\right.
$$

where $F_{E M}$ is the electromagnetic force, $\mathrm{N} ; F_{M}$ is the magnetomotive force, $\mathrm{A}$; $I$ is the coil current rate, $\mathrm{A}$; $W_{P W}$ is the number of pull-in coil turns; $R_{P W}$ is the resistance pull-in coil, Ohm; $U_{B}$ is the onboard electricity supply system voltage, $\mathrm{V}$.

Formula (1) implies that the pull-in coil magnetomotive force depends on its resistance. At the same time, all main coil malfunctions (turn-to-turn short circuits, short circuits to frame, coil breakage) cause its change [4]. Therefore, the electrical resistance of the coil can be used as the diagnostic parameter of the traction relay.

The coil resistance change is also caused by turn-toturn and body insulation resistance change.

In the normal operation condition, turn-to-turn and body insulation resistance (tens of MOhm) considerably exceeds the pull-in coil resistance (it is less than one Ohm) and has no impact on it. In case of the considerable insulation resistance decrease due to the exposure to destabilizing factors (moisture ingress, high temperature, corrosive agents), turn-to-turn short circuit or short circuit to frame occurs, causing the coil resistance reduction.

From this, the pull-in coil mathematical model is

$$
\left\{\begin{array}{l}
F_{M}=f\left(R_{P W}\right) \\
R_{P W} \rightarrow R_{P W N} \text { at } R_{c i}, R_{t i} \rightarrow \text { max }
\end{array}\right.
$$

and its normal operation condition is

$$
\left\{\begin{array}{l}
R_{P W}=R_{P W N}-\text { good condition } \\
0,5 \cdot R_{P W N} \leq R_{p W} \leq 2,0 \cdot R_{P W N}-\text { normal operation condition } \\
0,5 \cdot R_{P W N}>R_{P W}-\text { coil closing } \\
R_{P W}>2,0 \cdot R_{P W N}-\text { coil breakage }
\end{array}\right.
$$

As the pull-in coil should create the contact spring force $F_{E M}$ exceeding the return spring force $F_{s p}$, its decrease lower than this value can be considered the coil failure criterion. Figure 3 demonstrates two points in which the pull-in coil ceases performing its function; here, the right point corresponds to the coil conditional 


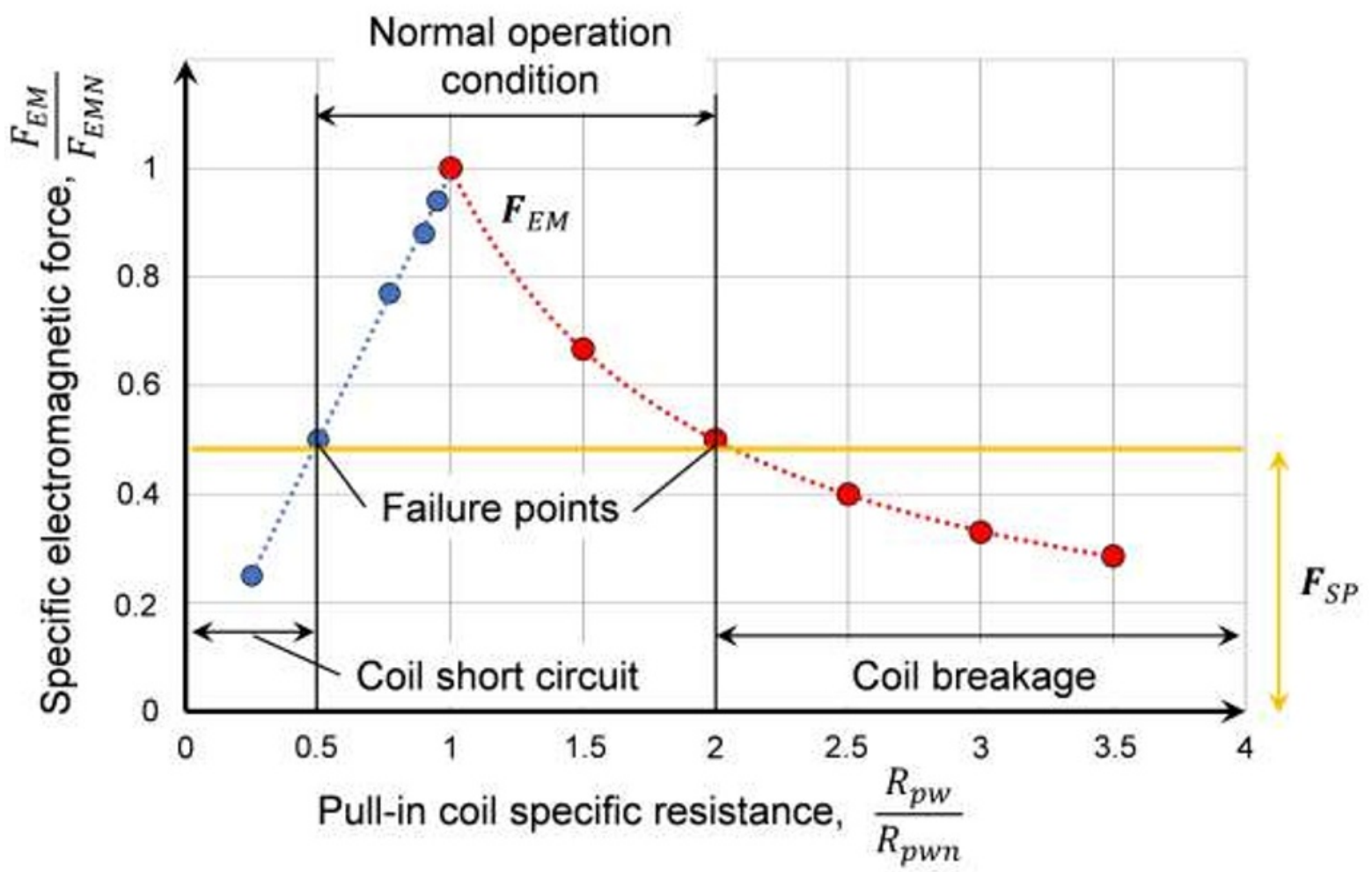

Fig. 3. Interaction between the technical condition of the traction relay pull-in coil and its electric resistance.

breakage, and the left point, to the coil conditional short circuit.

Similar computations are also typical for the hold-in coil, with the only difference that the force generated by it serves only for maintaining the tightened position of the traction relay armature.

Voltage supplied to the starter electric motor through the traction relay contacts can be expressed in the following form

$$
\left\{\begin{array}{l}
U_{S}=U_{B}-\Delta U_{T R} \\
\Delta U_{T R}=f\left(F_{C}, R_{C T R}\right)
\end{array}\right.
$$

where $U_{S}$ is the voltage on the starter electric motor, $\mathrm{V}$; $\Delta U_{T R}$ is the voltage loss on the traction relay contacts, $\mathrm{V}$; $R_{C T R}$ is the resistance of the traction relay contacts, Ohm; $F_{C}$ is the contact spring force, $\mathrm{N}$.

Then the normal operation condition for the traction relay contacts is

$$
\left\{\begin{array}{l}
F_{C}<F_{C N} \rightarrow \text { bad contact } \\
R_{C T P}=0 \rightarrow \text { welding of relay contacts } \\
R_{C T R}>R_{C T R N} \rightarrow \text { oxidation of relay contacts }
\end{array}\right.
$$

Thus, summary mathematical model of normal operation of motor-and-tractor starter traction relays will have the following form

$$
\left\{\begin{array}{l}
F=F_{E M}-F_{S P}=f\left(R_{P W}, R_{H W}\right)-F_{S P} \\
U_{S}=U_{B}-\Delta U_{T R}=U_{B}-f\left(F_{C}, R_{T R}\right)
\end{array}\right.
$$

where $F_{S P}$ is the return spring force, $\mathrm{N} ; R_{H W}$ is the holdin coil resistance, $\mathrm{Ohm}$.

\section{Experimental study research}

With the purpose to establish the distinct limit between the operable and inoperable condition of traction relays coils, the experiment on physical simulation of coil malfunctions with the adjustable active resistance was carried out.

Experimentation electrical circuit is given on Figure

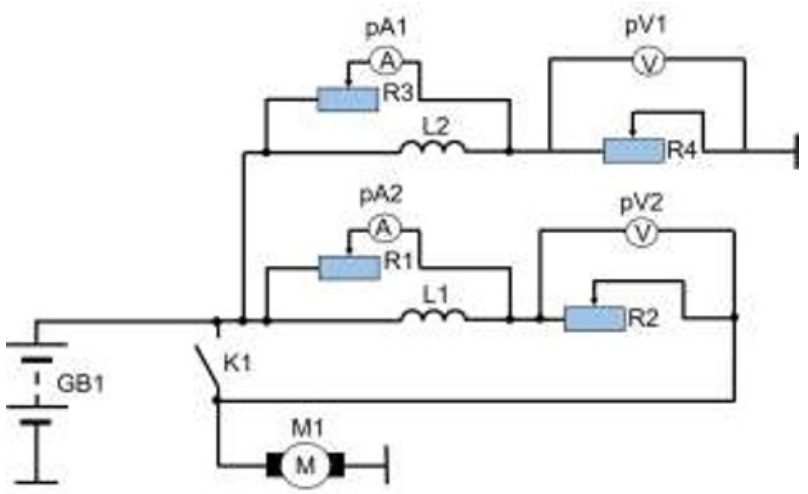

Fig. 4. Experimentation electrical circuit (GB1 - starter battery; K1 - traction relay contact; L1 - traction relay hold-in coil; L2 - traction relay pull-in coil; M1 - starter motor; pA1, pA2 - amperemeters; pV1, pV2 - voltmeters; R1-R4 - variable resistors simulating malfunctions).

For simulating the breakage of traction relay coils, adjustable active resistance (variable resistor) is 


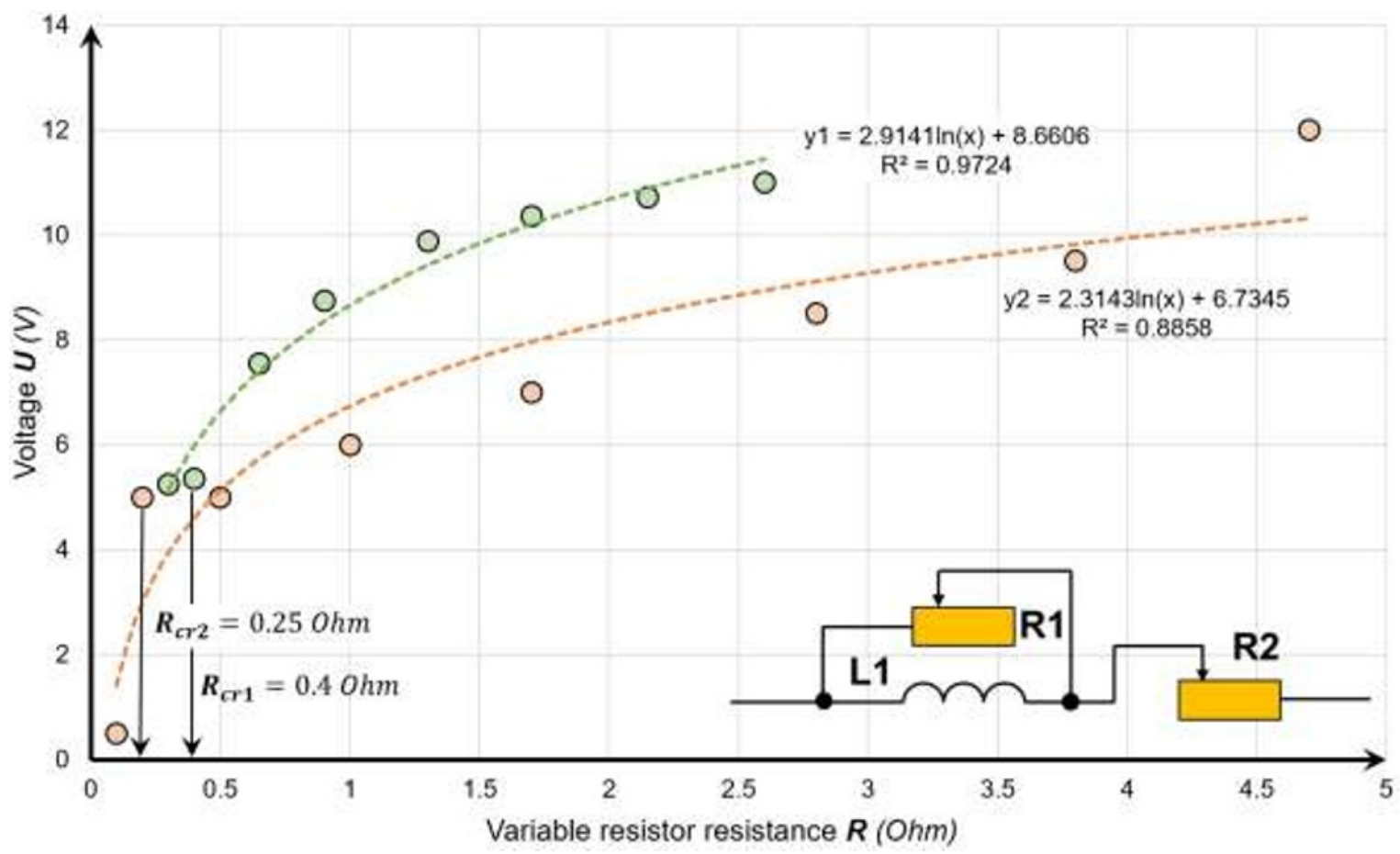

Fig. 5. Results of simulating malfunctions of the traction relay pull-in coil (1 - coil short circuit, 2 - coil breakage).

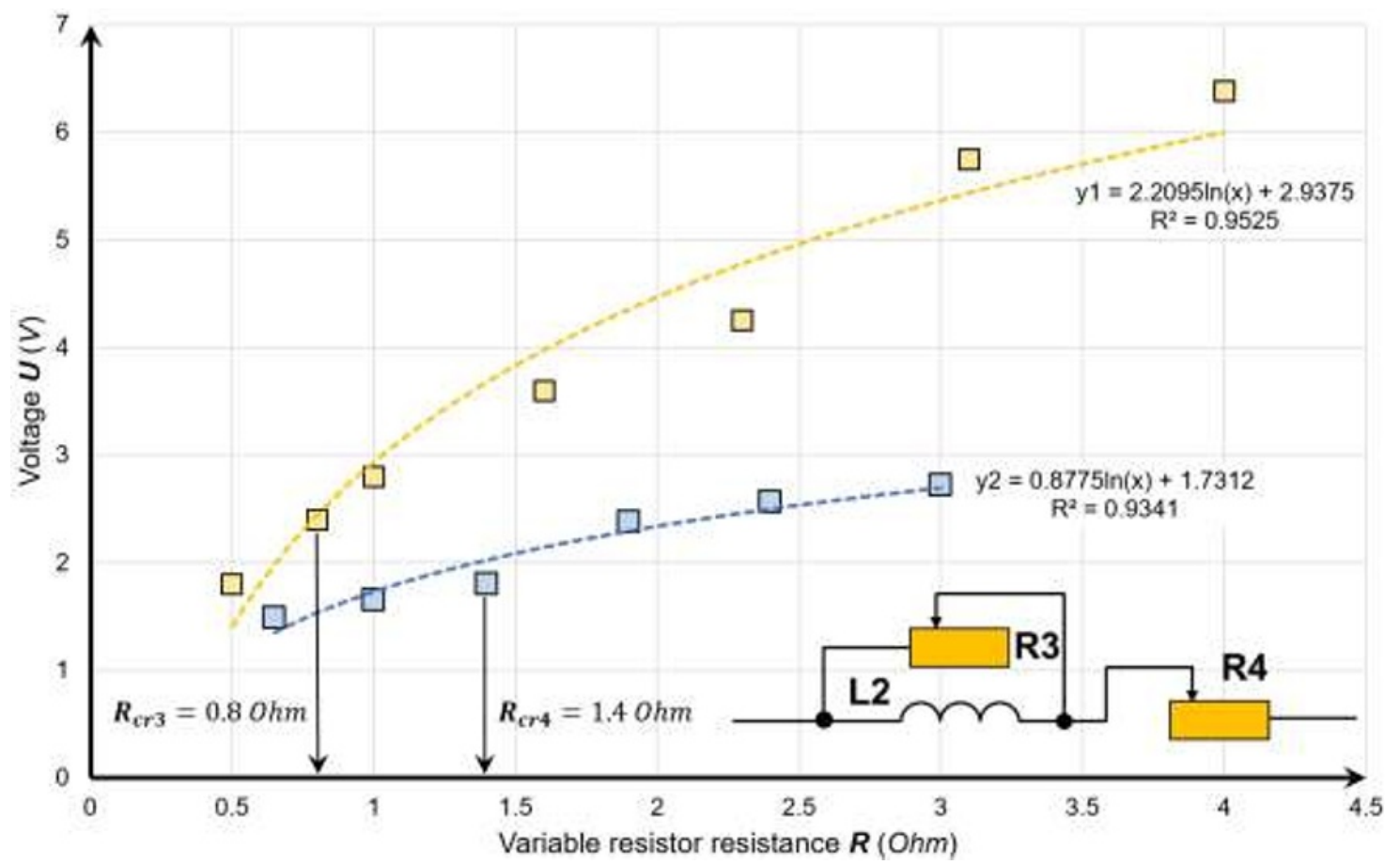

Fig. 6. Results of simulating malfunctions of the traction relay hold-in coil (3 - coil short circuit, 4 - coil breakage).

connected in series with coils, and for simulating short circuit, it is connected in parallel.

The results simulating the pull-in coil breakage (Figure 5) demonstrated that when reaching the critical value $R c r=0.4 \mathrm{Ohm}$, the traction relay armature ceases to be pulled in which means the traction relay failure. The short circuit simulation results demonstrated that the same effect is achieved by the parallel connection of the variable resistor with the resistance $R c r=0.25 \mathrm{Ohm}$.
The experiment on simulating the hold-in coil malfunctions, the results of which are given in Figure 6, was carried out in the similar way.

\section{Conclusion}

Malfunctions of motor starter traction relays (around $18 \%$ failures of starters) cause the impossibility to perform reliable startup of internal combustion engines 
which can cause the risk of traffic accident occurrence if the worst comes to the worst. Traction relay elements connected with the electric (electromagnetic) energy flow form the closed circuit. Consequently, the deviation of operating parameters of any of these elements (the extreme case is failure) will cause the reduction of the probability of ICE reliable startup.

The developed mathematical model of traction relay normal operation includes the amount of effort generated and voltage loss on contacts as controlled values for the drive mechanism and the starter electric motor, respectively. Electric resistances of traction relay coils are structural and diagnostic parameters at the same time. Critical values of electric resistances correspond to failures of traction relay coils, i.e., inability to perform the built-in functions. Further research will be aimed at obtaining the generalized mathematical model of motorand-tractor starters normal operation in the whole. The results obtained contribute to the development of the method of motor-and-tractor starter diagnostics without removing it from the engine

\section{References}

1. A.G. Sergeev, V.E. Yutt, Diagnostics of electric equipment of cars (1987)

2. S.K. Gnutov, Development and research of starter motors with high starting properties under low temperature conditions (2008)

3. A. V. Zayatrov, Comprehensive assessment of the quality and reliability of passenger car electrical equipment (2013)

4. M.I. Filatov, A.V. Puzakov, A.D. Kidanov, Development and justification of the method of diagnosing autotractor starters. Proceedings of the Orenburg State Agrarian University, 66, 118-121 (2017) 5. S. A. Feofanov, P.I. Buhteev, I.M. Denisov, Research to improve the traction relay automotive starter. Experimental and theoretical studies in modern science, Collection of articles on the materials of the I International Scientific and Practical Conference, 76-83 (2017)

6. K.I. Putilkin, O.A. Krutko, Evaluation of the reliability of the automotive starter, Science and Education: Vectors of Development I materials of the International Scientific and Practical Conference, 729731 (2013)

7. A.A. Severin, Mathematical modeling of abnormal operation modes of starters, Autotractor electrical equipment, 3, 21-23 (2004)

8. A.I. Rau, Pattern-automotive starter defects, APRIORI. Series: Natural and technical sciences, 5, 2327 (2015)

9. V.N. Kozlovsky, Ensuring the quality and reliability of the vehicle electrical system (2010)

10. A.A. Lazarev, Improvement of the electric starting system for internal combustion engines (2009)

11. S.S. V. QiMa Rajagopalan, S. Yurkovich, Y.G. Guezennec, A high-fidelity starter model for engine start simulations, American Control Conference, 7, 44234427 (2005)

12. R. Bayir, O.F. Bay, Serial Wound Starter Motor Faults Diagnosis Using Artificial Neural Network, IEEE International Conference, Mechatronics, 194-199 (2004) 13. R. Bayir, Condition Monitoring and Fault Diagnosis of Serial Wound Starter Motor with Learning Vector Quantization Network, Journal of Applied Sciences, 3148-3156 (2008)

14. R. Bayir, O.F. Bay, A Fault Diagnosis of Engine Starting System Via Starter Motors Using Fuzzy Logic Algorithm, Gazi University Journal of Science, 24(3), 437-449 (2011)

15. S.S.H. Zaidi, S. Aviyente, Prognosis of Gear Failures in DC Starter Motors Using Hidden Markov Models, IEEE Transactions on Industrial Electronics, 58(5) (2011)

16. S.S.H. Zaidi, S. Aviyente, Failure Prognosis of DC Starter Motors Using Hidden Markov Models (2009)

17. V.M. Murugesan, G. Chandramohan, M. Senthil Kumar, R. Rudramoorthy, L. Ashok Kumar, R. Suresh Kumar, D. Basha, K. Vishnu Murthy, An overview of automobile starting system faults and fault diagnosis methods, ARPN Journal of Engineering and Applied Sciences, 7, 812-819 (2012)

18. M.I. Filatov, A.V. Puzakov, A.D. Kidanov, Proceedings of the Orenburg State Agrarian University, 68, 86-88 (2017) 